\title{
Prognostic value of coronary CT angiography on long-term follow-up of 6.9 years
}

Dougoud, Svetlana ; Fuchs, Tobias A ; Stehli, Julia ; Clerc, Olivier F ; Buechel, Ronny R ; Herzog, Bernhard A ; Leschka, Sebastian ; Alkadhi, Hatem ; Kaufmann, Philipp A ; Gaemperli, Oliver

\begin{abstract}
Long term follow-up of coronary CT angiography (CCTA) is scarce. The aim of the present study was to assess the prognostic value of CCTA over a follow-up period of more than 6 years. 218 Patients were included undergoing 64-slice CCTA. Images were analysed with regard to the presence of nonobstructive $(<50 \%)$ or obstructive (50\% stenosis) coronary artery disease (CAD). Major adverse cardiovascular events (MACE) were defined as death, nonfatal myocardial infarction or urgent coronary revascularization. CCTA revealed normal coronaries in 49, nonobstructive lesions in 94, and obstructive CAD in 75 patients. During a median follow-up period of 6.9 years, MACE occurred in 45 patients (21\%). Annual MACE rates were 0.3, 2.7, and $6.0 \%(\mathrm{p}=0.001)$, for patients with normal CCTA, nonobstructive, and obstructive CAD, respectively. Multivariate Cox regression analysis identified the number of segments with plaques [hazard ratio $(\mathrm{HR}) 1.18, \mathrm{p}=0.002$ ] as well as the presence of obstructive lesions (HR 2.28, $\mathrm{p}=0.036$ ) as independent predictors of MACE. The present study extends the predictive value of CCTA over more than 6 years. Patients with normal coronary arteries of CCTA continue to have an excellent cardiac prognosis, while outcome is progressively worse in patients with nonobstructive and obstructive CAD.
\end{abstract}

DOI: https://doi.org/10.1007/s10554-014-0420-1

Posted at the Zurich Open Repository and Archive, University of Zurich

ZORA URL: https://doi.org/10.5167/uzh-95120

Journal Article

Published Version

Originally published at:

Dougoud, Svetlana; Fuchs, Tobias A; Stehli, Julia; Clerc, Olivier F; Buechel, Ronny R; Herzog, Bernhard A; Leschka, Sebastian; Alkadhi, Hatem; Kaufmann, Philipp A; Gaemperli, Oliver (2014). Prognostic value of coronary CT angiography on long-term follow-up of 6.9 years. International Journal of Cardiovascular Imaging, 30(5):969-976.

DOI: https://doi.org/10.1007/s10554-014-0420-1 


\title{
Prognostic value of coronary CT angiography on long-term follow-up of 6.9 years
}

\author{
Svetlana Dougoud $\cdot$ Tobias A. Fuchs $\cdot$ Julia Stehli $\cdot$ Olivier F. Clerc • \\ Ronny R. Buechel • Bernhard A. Herzog • Sebastian Leschka • \\ Hatem Alkadhi · Philipp A. Kaufmann • Oliver Gaemperli
}

Received: 24 February 2014/ Accepted: 3 April 2014/Published online: 8 April 2014

(C) Springer Science+Business Media Dordrecht 2014

\begin{abstract}
Long term follow-up of coronary CT angiography (CCTA) is scarce. The aim of the present study was to assess the prognostic value of CCTA over a follow-up period of more than 6 years. 218 Patients were included undergoing 64-slice CCTA. Images were analysed with regard to the presence of nonobstructive $(<50 \%)$ or obstructive (50\% stenosis) coronary artery disease (CAD). Major adverse cardiovascular events (MACE) were defined as death, nonfatal myocardial infarction or urgent coronary revascularization. CCTA revealed normal coronaries in 49 , nonobstructive lesions in 94, and obstructive CAD in 75 patients. During a median follow-up period of 6.9 years, MACE occurred in 45 patients ( $21 \%)$. Annual MACE rates were $0.3,2.7$, and $6.0 \%(p=0.001)$, for patients with
\end{abstract}

Svetlana Dougoud and Tobias A. Fuchs have contributed equally to this work and share first coauthorship.

Philipp A. Kaufmann and Oliver Gaemperli have contributed equally to this work and share last coauthorship.

S. Dougoud - T. A. Fuchs · J. Stehli · O. F. Clerc $\cdot$

R. R. Buechel · B. A. Herzog · P. A. Kaufmann .

O. Gaemperli $(\bowtie)$

Cardiac Imaging, University Hospital Zurich, Ramistrasse 100,

NUK C 42, 8091 Zurich, Switzerland

e-mail: oliver.gaemperli@usz.ch

S. Leschka $\cdot$ H. Alkadhi

Institute of Diagnostic and Interventional Radiology, University

Hospital Zurich, Zurich, Switzerland

S. Leschka

Institute of Radiology, Kantonsspital St. Gallen, St. Gallen,

Switzerland

P. A. Kaufmann

Zurich Center for Integrative Human Physiology (ZIHP),

University of Zurich, Zurich, Switzerland normal CCTA, nonobstructive, and obstructive CAD, respectively. Multivariate Cox regression analysis identified the number of segments with plaques [hazard ratio (HR) $1.18, p=0.002]$ as well as the presence of obstructive lesions (HR 2.28, $p=0.036$ ) as independent predictors of MACE. The present study extends the predictive value of CCTA over more than 6 years. Patients with normal coronary arteries of CCTA continue to have an excellent cardiac prognosis, while outcome is progressively worse in patients with nonobstructive and obstructive CAD.

Keywords CT coronary angiography $\cdot$ Prognosis $\cdot$ Longterm follow up

\section{Introduction}

Coronary CT angiography (CCTA) is widely used for the noninvasive evaluation of suspected coronary artery disease (CAD) and can accurately depict nonobstructive or obstructive coronary lesions. Several single- and multi-center reports have documented that findings on CCTA are strong and independent predictors of short-term cardiovascular risk [1] Specifically, the presence of coronary atheromata, their number and distribution, the presence of obstructive coronary stenoses and even their composition have been advocated as potential predictors for future cardiovascular events [2-5]. The CONFIRM registry has confirmed these results in a large multicentric and multiethnic population of more than 23,000 patients and a mean follow-up of 2.3 years [6].

However, the majority of published reports had a somewhat short follow-up (2-3 years) and reports with longer follow-up are scarce [7, 8]. This is related to the fact that CCTA is a relatively novel technique which found wide acceptance with the introduction of the 64-detector 
systems in 2005-2006. However, longer-term follow-up is imperative if the results from CCTA are to be implemented in clinical practice and used to guide long-term or even life-long therapies to reduce cardiovascular risk.

Thus, the aim of the present study was to investigate whether the prognostic value of CCTA is maintained over a longer follow-up of more than 6 years and to identify key imaging findings with an impact on long-term prognosis.

\section{Materials and methods}

Patient population and study design

Between January 2005 and July 2007, we included consecutive patients undergoing CCTA at the Cardiac Imaging Center, University Hospital Zurich. The study population was in part shared with a previously reported registry on short term outcome prediction by CCTA [2]. Reasons for referral were typical or atypical chest pain, pathological exercise test, dyspnea and preoperative cardiac risk evaluation. Patients with previous coronary artery bypass grafting $(\mathrm{CABG})$ were excluded. The need for written inform consent was waived by the institutional review board (local ethics committee) because of the purely retrospective nature of the study.

\section{CCTA image acquisition}

CCTA image acquistion was performed on a 64-slice CT system (GE Lightspeed VCT, GE Healthcare, Milwaukee, WI, or Siemens Somatom Sensation 64, Siemens Medical Solutions, Forchheim, Germany) as previously published [2]. In brief, patients underwent unenhanced prospectively triggered low-dose sequential CT scan of the heart for coronary artery calcium (CAC) scoring followed by a contrast-enhanced retrospectively gated spiral CT scan. Eighty to $135 \mathrm{ml}$ nonionic iodinated contrast material (Visipaque 320, $320 \mathrm{mg} / \mathrm{ml}$; GE Healthcare, Buckinghamshire, UK, or Ultravist $370,370 \mathrm{mg} / \mathrm{ml}$, Schering AG, Berlin, Germany) was injected into an antecubital vein with a flow rate of $5 \mathrm{ml} / \mathrm{s}$ followed by a saline chaser bolus. Pre-scan intravenous beta blocker (metoprolol tartrate, Lopresor, Daiichi Sankyo, Switzerland) was administrated if heart rate was above 70 beats/min (bpm) and sublingual isosorbiddinitrat (Isoket, Schwarz Pharma AG, Munchenstein, Switzerland) if there were no contraindications. ECG-pulsing for radiation dose reduction was used in all patients. Synchronized to ECG, CT data sets were retrospectively reconstructed in mid- to end-diastolic phases and additional phases if needed for optimal coronary artery visualization. For post-processing and image interpretation, the images were then transferred to an external designated workstation (Advantage Workstation, GE, or Leonardo, Siemens).

\section{CCTA image interpretation}

Axial source images, multiplanar and curved reformations as well as thin-slab maximum intensity projections were used for CCTA image interpretation. The coronary arteries were then subdivided into 17 segments according to a model proposed by American Heart Association [9]. Images were evaluated by consensus of two readers with experience in cardiac imaging (P. A. K. with 10 years of experience in cardiac radionuclide imaging and $\mathrm{H}$. A. with 1 year of experience in cardiac CT). Image quality and interpretability were assessed for each segment. Segments were defined as nonevaluable if they had severe motion artifacts and/or severe calcifications obscuring the coronary lumen. Patients were excluded if one or more proximal segments or more than three segments overall were nonevaluable. Segments smaller than $1.5 \mathrm{~mm}$ diameter were not included in the analysis.

A coronary plaque was defined as a structure $\geq 1 \mathrm{~mm}^{2}$ within and/or adjacent to the coronary artery lumen, which could be clearly distinguished from the vessel lumen and the surrounding pericardial/myocardial tissue. The composition of plaques was characterized based on the presence of calcifications as previously reported [2] and plaques sub-classified into: (1) noncalcified, (2) mixed, and (3) calcified plaques. The number of coronary segments per patient with plaques was calculated and given as segment involvement score (SIS). A coronary plaque was defined as obstructive if the minimal luminal diameter was less than $50 \%$ of the adjacent reference diameter in either the longitudinal section or one of the cross-sections [10]. The number and location of affected segments were recorded for each patient. Patients without evidence of coronary plaques on CCTA and without coronary calcium on CACS scans were considered to have normal coronary arteries.

\section{Coronary artery calcium score (CACS)}

Coronary artery lesions were manually planimetered by a single experienced observer and the total calcium burden in the coronaries was quantified based on the scoring algorithm of Agatston et al. [11]. The four main arteries were investigated in all slices and the total calcium burden was summed to generate the total score.

\section{Follow-up}

The following endpoints were recorded: death, nonfatal myocardial infarction (MI), or late revascularization [with either percutaneous coronary intervention (PCI) or CABG]. 
All revascularization procedures within 90 days of the CCTA study were excluded from the follow-up analysis, as they were considered to have been triggered directly by the CCTA findings. Nonfatal MI was defined according to the current universal definition of Thygesen et al. [12]. Major adverse cardiovascular events (MACE) was defined as the composite endpoint of death, MI, and revascularization.

\section{Statistical analysis}

Statistical analysis was performed using the SPSS software package (SPSS 12.0.1 for Windows, SPSS Corp., Chicago, IL). Categorical data were expressed in proportions or percentages and quantitative data were given as mean $\pm \mathrm{SD}$ or median and interquartile range (IQR) where appropriate. Differences between groups were assessed using the Chi square test for categorical and Mann-Whitney U test or Student's $t$ test for continuous variables. A $p$ value $<0.05$ was considered statistically significant for all tests. To analyze the follow-up data we obtained cumulative event rates using the Kaplan-Meier function. Eventfree survival curves were plotted for a composite endpoint of death, MI and coronary revascularization and compared using the log-rank test. Receiver-operating characteristics (ROC) analysis was employed to determine the best SIS cut-off to discriminate the likelihood of MACE. The optimal cut-off point was determined by using the Youden index ( $\mathrm{J}$ value) (calculated as the maximum of $\mathrm{J}=\mathrm{SN}+\mathrm{SP}-1$, where $\mathrm{SN}$ is sensitivity and $\mathrm{SP}$ is specificity, for each cutoff value [13]. Univariate and multivariate Cox proportional hazard regression models were applied to identify independent predictors of cardiac events. Variables were selected in a stepwise forward selection manner; entry and retention sets with a $p<0.05$ were considered to indicate a significant difference. Variables included in the models were age, gender, history of $\mathrm{CAD}$, previous $\mathrm{MI}$, hypertension, hypercholesterolemia, diabetes mellitus, smoking, CACS, presence of coronary plaques, presence of coronary stenosis and the SIS. The regression results are expressed as hazard ratios (HR) and their respective confidence intervals (CI).

\section{Results}

Between January 2005 and July 2007, we enrolled 268 patients who underwent CCTA at our institution. Twentythree patients $(9 \%)$ had to be excluded due to poor CCTA image quality. Twenty-seven $(10 \%)$ were lost to followup. Thus, 218 patients were included in the analysis.

The mean age of the study population was $62 \pm 10$ years and 82 patients were female ( $38 \%$ ). The detailed clinical characteristics are given in Table 1.
CCTA findings

In 218 patients a total of 3,043 coronary segments were evaluated. After exclusion of four segments due to insufficient image quality, plaque burden and composition were assessed in 3,039 segments. Coronary plaques were found in 731 segments $(24 \%)$. Of these plaques, $30(4 \%)$ were non-calcified, $209(29 \%)$ mixed and $492(67 \%)$ calcified. Obstructive lesions were identified in 196 segments (6\%).

The median Agatston score was 90 (range 0-3,968). We identified 75 patients $(34 \%)$ with obstructive CAD, of which $32(15 \%)$ had one-vessel, 28 (13\%) two-vessel, and $15(7 \%)$ three-vessel disease. Two patients (1\%) had obstructive left main disease (non-isolated). In 49 patients (22\%), normal coronary arteries without radiological evidence for coronary plaques were found. The CT findings are summarized in Table 2.

\section{Cardiovascular events}

During a median follow-up of 6.9 years (IQR 6.3-7.3 years), at least one of the predefined endpoints occurred in 45 patients $(21 \%)$. Overall, we recorded 20 deaths $(9 \%)$ and 8 MI (4\%). In 20 patients $(9 \%)$ a late revascularization was performed [CABG $(\mathrm{n}=5)$, PCI $(n=15)]$. Table 3 summarizes the follow-up results in the study population.

\section{Survival analysis}

Figure 1 shows the Kaplan-Meier event-free survival curves. Patients with normal coronary arteries on CCTA (e.g., no coronary artery plaques or stenosis present) had an excellent event-free survival. Only one patient of those with normal coronary arteries had an event which did not appear to be cardiac (death from septic shock) (Table 3). By contrast, prognosis was progressively worse in patients with non-obstructive and obstructive CAD (Fig. 1).

The highest annual event rate for MACE was noted in patients with obstructive lesions on CCTA (6.0\%). Event rates were lower in patients with non-obstructive CAD $(2.7 \%)$, and were very low in patients with normal coronary arteries $\quad(0.3 \%) \quad(p<0.001) \quad$ (Fig. 2). The annual event rate for the composite endpoints death and MI was $1.9 \%$ for all patients $(3.0 \%$ for patients with obstructive CAD, $1.9 \%$ for patients with non-obstructive CAD, $0.3 \%$ for patients without CAD respectively, $p=0.018$ ).

ROC curve analysis yielded a cut-off at $\geq 4$ coronary plaques as optimal cut-off providing highest accuracy for the prediction of MACE on follow-up (area under curve 0.76). Consequently prognosis was worse in patients with a SIS $\geq 4$ compared to patients with SIS $<4$ (Fig. 3). 
Table 1 Clinical characteristics of the study population

Data not shown as $\mathrm{n}(\%)$ are mean $\pm \mathrm{SD}$

$A C E I$ angiotensin converting enzyme inhibitor, $A R B$

angiotensin receptor blockers, $C A D$ coronary artery disease, $C A B G$ coronary artery bypass grafting, $M I$ myocardial infarction, $P C I$ percutaneous coronary intervention

Table 2 CT-findings

Data not shown as $\mathrm{n}(\%)$ are mean \pm SD

CTA computed tomography angiography, $C A D$ coronary artery disease

${ }^{\text {a }}$ Calcium score is given as Agatston score as median and interquartile range

\begin{tabular}{|c|c|c|c|c|}
\hline & $\begin{array}{l}\text { All patients } \\
(\mathrm{n}=218)\end{array}$ & $\begin{array}{l}\text { Patients with events } \\
(\mathrm{n}=45)\end{array}$ & $\begin{array}{l}\text { Patients without events } \\
(\mathrm{n}=173)\end{array}$ & $p$ \\
\hline Age (years) & $62 \pm 10$ & $65 \pm 11$ & $61 \pm 10$ & 0.06 \\
\hline Female gender $[\mathrm{n}(\%)]$ & $82(38 \%)$ & $13(29 \%)$ & $69(40 \%)$ & 0.18 \\
\hline $\mathrm{BMI}\left(\mathrm{kg} / \mathrm{m}^{2}\right)$ & $27 \pm 4$ & $27 \pm 4$ & $27 \pm 4$ & 0.93 \\
\hline \multicolumn{5}{|c|}{ Cardiovascular risk factor [n (\%)] } \\
\hline Obesity & $43(20 \%)$ & $7(16 \%)$ & $36(21 \%)$ & 0.43 \\
\hline Diabetes mellitus & $31(14 \%)$ & $10(22 \%)$ & $21(12 \%)$ & 0.08 \\
\hline Hypercholesterolemia & $98(45 \%)$ & $23(51 \%)$ & $75(43 \%)$ & 0.35 \\
\hline Arterial hypertension & $128(59 \%)$ & $26(58 \%)$ & $102(59 \%)$ & 0.88 \\
\hline $\begin{array}{l}\text { Family history of } \\
\text { CAD }\end{array}$ & $56(26 \%)$ & $14(31 \%)$ & $42(24 \%)$ & 0.35 \\
\hline Current smoking & $79(36 \%)$ & $25(56 \%)$ & $54(31 \%)$ & 0.003 \\
\hline \multicolumn{5}{|c|}{ Current medication [n (\%)] } \\
\hline ACEI/ARB & $83(38 \%)$ & $21(47 \%)$ & $62(36 \%)$ & 0.18 \\
\hline Nitrates & $17(8 \%)$ & $4(9 \%)$ & $13(8 \%)$ & 0.76 \\
\hline $\begin{array}{l}\text { Beta-receptor } \\
\text { antagonists }\end{array}$ & $87(40 \%)$ & $19(42 \%)$ & $68(39 \%)$ & 0.72 \\
\hline Aspirin & $121(56 \%)$ & $26(58 \%)$ & $95(55 \%)$ & 0.73 \\
\hline Statins & $73(33 \%)$ & $13(29 \%)$ & $60(35 \%)$ & 0.46 \\
\hline \multicolumn{5}{|l|}{ Cardiac history [n (\%)] } \\
\hline Known CAD & $31(14 \%)$ & $12(27 \%)$ & $19(11 \%)$ & 0.007 \\
\hline Previous MI & $17(8 \%)$ & $7(16 \%)$ & $10(6 \%)$ & 0.03 \\
\hline Previous PCI & $28(13 \%)$ & $8(18 \%)$ & $20(12 \%)$ & 0.27 \\
\hline
\end{tabular}

\begin{tabular}{lllll}
\hline & $\begin{array}{l}\text { All patients } \\
(\mathrm{n}=218)\end{array}$ & $\begin{array}{l}\text { Patients with events } \\
(\mathrm{n}=45)\end{array}$ & $\begin{array}{l}\text { Patients without events } \\
(\mathrm{n}=173)\end{array}$ & $p$ \\
\hline $\begin{array}{l}\text { Total calcium score } \\
\text { Coronary plaques n in CTA }\end{array}$ & $90(0-490)$ & $478(204-1,212)$ & $34(0-356)$ & $<0.001$ \\
$\begin{array}{c}\text { No plaques, CTA } \\
\text { normal }\end{array}$ & $49(22 \%)$ & $1(2 \%)$ & $48(28 \%)$ & $<0.001$ \\
$\begin{array}{l}\text { Segment } \\
\text { involvement score }\end{array}$ & $3.4 \pm 3.1$ & $5.5 \pm 3.0$ & $2.8 \pm 2.9$ & $<0.001$ \\
$\begin{array}{c}\text { Nonobstructive } \\
\text { plaques only }\end{array}$ & $94(43 \%)$ & $15(33 \%)$ & $79(46 \%)$ & 0.14 \\
$\begin{array}{c}\text { Obstructive plaques } \\
\text { Left-main disease }\end{array}$ & $75(34 \%)$ & $29(64 \%)$ & $46(27 \%)$ & $<0.001$ \\
$\begin{array}{l}\text { One-vessel disease } \\
\text { Two-vessel disease }\end{array}$ & $32(15 \%)$ & $11(24 \%)$ & $1(1 \%)$ & 0.30 \\
$\begin{array}{l}\text { Three-vessel } \\
\text { disease }\end{array}$ & $15(7 \%)$ & $13(29 \%)$ & $21(12 \%)$ & 0.04 \\
Left dominance & $20(9 \%)$ & $2(4 \%)$ & $15(9 \%)$ & $<0.001$ \\
\hline
\end{tabular}

\section{Predictors of outcome}

The results of univariate Cox regression analysis applied for clinical characteristics, cardiovascular risk factors and CT findings are shown in Table 4. Smoking was the only cardiovascular risk factor significantly associated with an increased incidence of cardiac events on follow-up $(p=0.002)$. Of the
CCTA findings, the presence of coronary plaques $(p=0.009)$, the presence of obstructive CAD $(p<0.001)$ and the SIS $(p<0.001)$ were predictive of a higher event rate. When multivariate Cox regression analysis was employed, correcting for baseline clinical characteristics and risk factors, the presence of coronary stenoses $(p=0.036)$ and the SIS $(p=0.002)$ emerged as the only independent predictors of MACE. 
Table 3 Follow-up results

\begin{tabular}{|c|c|c|c|c|c|}
\hline & $\begin{array}{l}\text { All Patients } \\
(\mathrm{n}=218)\end{array}$ & $\begin{array}{l}\text { Patients with } \\
\text { obstructive } \\
\text { CAD }(n=75)\end{array}$ & $\begin{array}{l}\text { Patients with } \\
\text { non-obstructive } \\
\text { CAD }(n=94)\end{array}$ & $\begin{array}{l}\text { Patients without } \\
\text { CAD }(\mathrm{n}=49)\end{array}$ & $p$ \\
\hline MACE $[\mathrm{n}(\%)]$ & $45(21 \%)$ & $29(39 \%)$ & $15(16 \%)$ & $1(2 \%)$ & $<0.001$ \\
\hline All-cause mortality & $20(9 \%)$ & $9(12 \%)$ & $10(11 \%)$ & $1(2 \%)$ & 0.14 \\
\hline Myocardial infarction & $8(4 \%)$ & $6(8 \%)$ & $2(2 \%)$ & $0(0 \%)$ & 0.04 \\
\hline Revascularization $^{\mathrm{a}}$ & $20(9 \%)$ & $15(20 \%)$ & $5(5 \%)$ & $0(0 \%)$ & $<0.001$ \\
\hline CABG & $5(2 \%)$ & $4(5 \%)$ & $1(1 \%)$ & $0(0 \%)$ & 0.09 \\
\hline PCI & $15(7 \%)$ & $11(15 \%)$ & $4(4 \%)$ & $0(0 \%)$ & 0.0028 \\
\hline
\end{tabular}

Values are depicted in $\mathrm{n}(\%)$

$M A C E$ major cardiac event (myocardial infarction, death, revascularization), $C A B G$ coronary artery bypass grafting, $P C I$ percutaneous coronary intervention

${ }^{a}$ Revascularization within 3 months of the CT Scan were not included

\section{Discussion}

The present study expands the prognostic value of CCTA over a long follow-up period of more than 6 years, and thereby builds on existing prospective CCTA studies with shorter follow-up. In particular, it documents an excellent long-term prognosis of normal (plaque-free) coronary arteries on CCTA with a very low likelihood for cardiac events on follow-up. Indeed, there was only one death in the group of patients with normal coronary arteries on CCTA, which was most probably unrelated to a cardiac etiology (septic shock). However, the prognosis was progressively worse in patients with non-obstructive and obstructive CAD with cardiac event rates (death/MI) of 1.9 and $3.0 \%$, respectively. In a multivariate Cox regression model, corrected for several baseline clinical characteristics and cardiovascular risk factors (including age, gender, history of $\mathrm{CAD}$, diabetes, hypertension and others) the only significant independent predictors of MACE were the number of coronary segments affected by atherosclerotic plaques and the presence of obstructive CAD on CCTA.

To our knowledge, this is the longest follow-up so far obtained in a cohort of patients undergoing state-of-the art 64-slice CCTA. Slightly longer follow-up (78 months) has been obtained with electron-beam CT (EBCT) [14]. Ostrom and colleagues demonstrated comparably low event rates for patients with normal coronary arteries on EBCT, and a progressive increase in event rates with non-obstructive and obstructive CAD. However, EBCT offers limited spatial resolution compared to CCTA. With state-of-the-art 64-slice CCTA or higher-end devices, isotropic sub-millimeter spatial resolution is easily achieved, which improves the detection of smaller, particularly non-calcified plaques. Our very low event rate of $0.3 \%$ year in patients with completely normal coronary arteries confirms the results of the recent large CONFIRM registry [6], which showed a comparably low event rate, and extends these results over a longer period of time. Our results are in line with a recent publication by Andreini et al. [7] who followed 1,304 patients for more than 4 years and reported a similar progressive increase in event rates for patients with nonobstructive and obstructive CAD. Sozzi et al. reported a slightly lower MACE rate compared to our results during a follow-up of 5 years. MACE rates were $0,1.2$ and $4.2 \%$ for patients with normal coronary arteries, non-obstructive and obstructive CAD respectively, albeit excluding death as an endpoint [8].

Hadamitzsky et al. followed 1,584 patients for 5.6 years and found slightly lower annual death/MI rates at $0.2,1.1$ and $1.5 \%$ for normal coronaries, non-obstructive and obstructive CAD, respectively. However in this report, patients were on average 4 years younger, had lower prevalence of diabetes and lower overall calcium scores compared to our study population [15]. In the CASS registry, 7-year death-rates in 3,136 patients with normal coronary arteries at invasive angiography was $4 \%$, hence slightly higher compared to the $0.3 \%$ death rate for a normal CCTA. This indicates that a "normal" invasive angiogram may overlook the presence of non-stenotic eccentric plaque, with potential impact on patient prognosis.

Among patients with non-obstructive CAD on CCTA, we observed a low event rate during the first 3 years of follow-up (only slightly higher than among patients with normal coronary arteries). However, in contrast to the prior publication by Andreini et al. event rates increased significantly in the second period of observation (the second 3 years). As a result, separation of survival curves for the group with normal coronary arteries and the group with non-obstructive CAD occurred only after approximately 3 years. This suggests that the lack of obstructive CAD on CCTA may provide a "warranty period" of approximately 3 years during which event rates are rather low. This is in keeping with a recent hybrid SPECT (single photon 
A

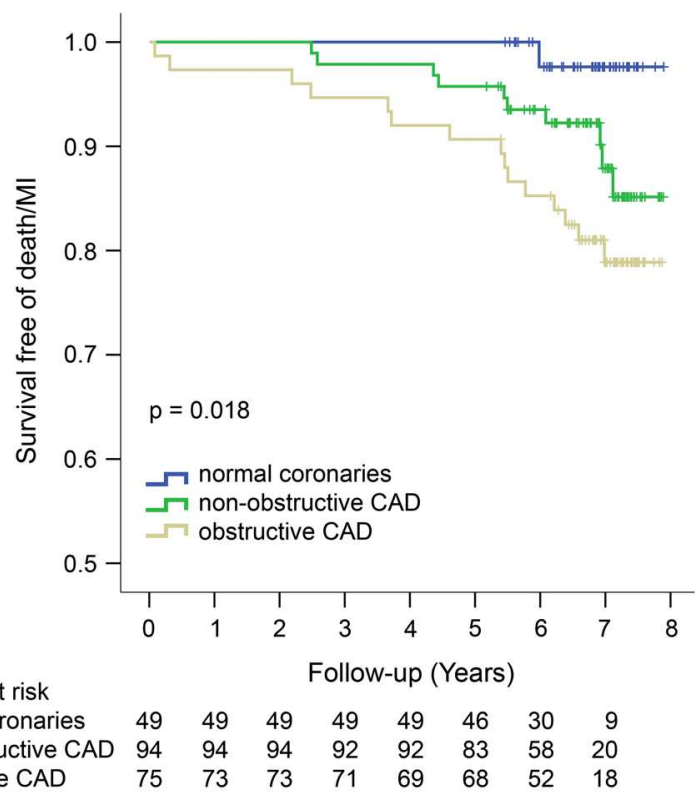

B

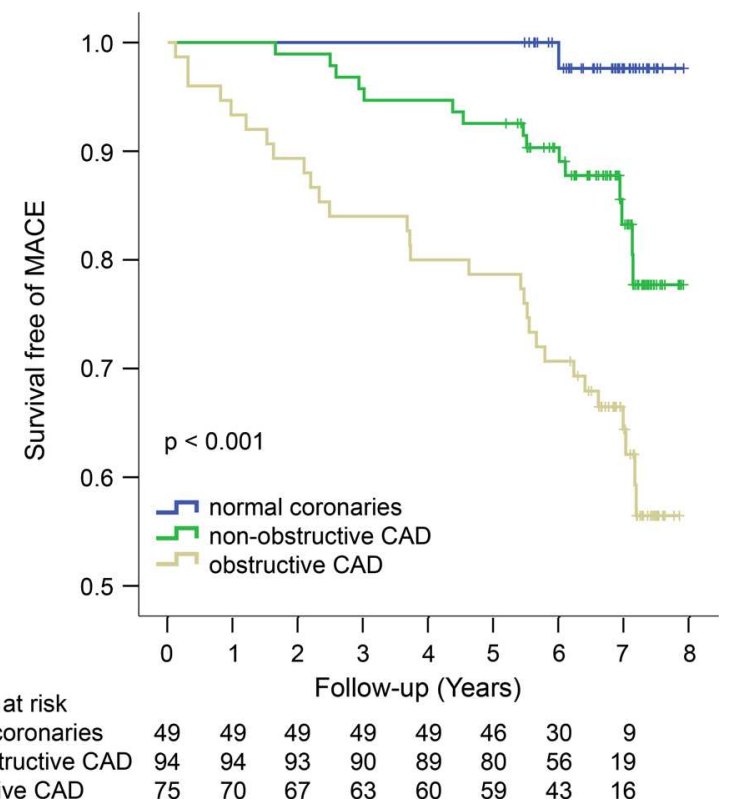

Number at risk $\begin{array}{lllllllll}\text { normal coronaries } & 49 & 49 & 49 & 49 & 49 & 46 & 30 & 9\end{array}$ $\begin{array}{lllllllll}\text { non-obstructive CAD } & 94 & 94 & 93 & 90 & 89 & 80 & 56 & 19 \\ \text { obstructive CAD } & 75 & 70 & 67 & 63 & 60 & 59 & 43 & 16\end{array}$

Fig. 1 Kaplan-Meier analysis for event-free survival of death/ myocardial infarction (a) or death/myocardial infarction/revascularization (b) in patients with normal coronaries, non-obstructive and obstructive coronary lesions on CT angiography

emission computed tomography)/CT study by Chang and colleagues, which assessed the incremental prognostic value of coronary artery calcium score (CACS) over myocardial perfusion in 1,126 subjects with normal SPECT scans [16]. There was a 2.8 -fold relative increase for death/ MI when the CACS was severe $(>400)$ versus minimal $(\leq 10)$ despite normal SPECT scans. Interestingly, separation of the survival curves occurred at 3-5 years. When integrated with our findings, this indicates, that if coronary atherosclerosis (by either CACS or CCTA) is severe, the

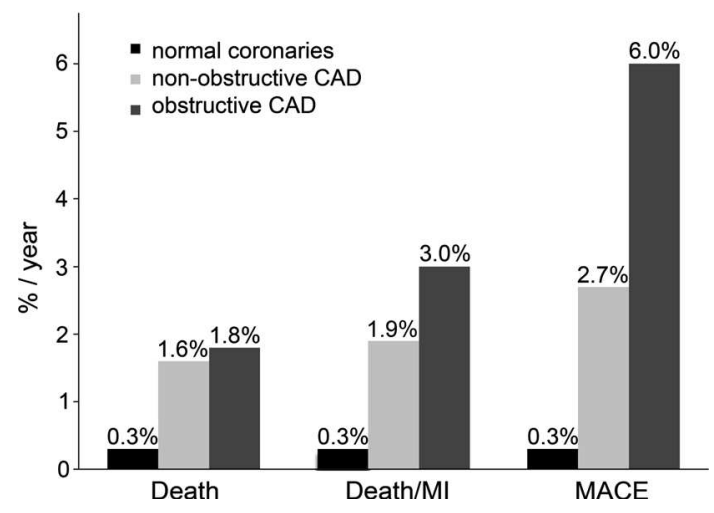

Fig. 2 Annual event rates for patients with normal coronaries, nonobstructive coronary artery disease $(C A D)$, and obstructive CAD

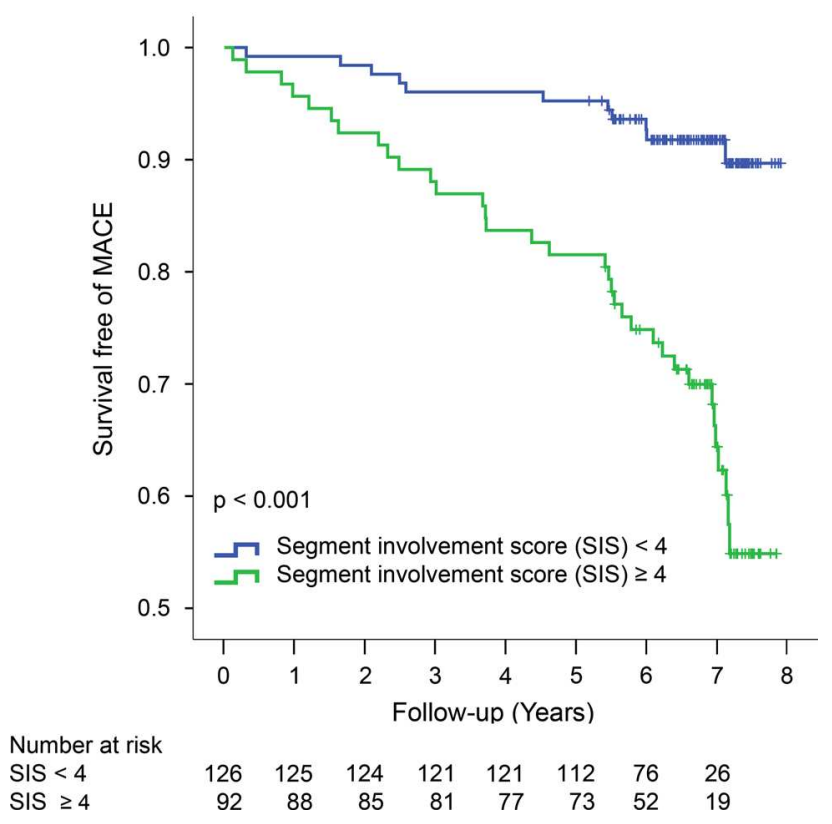

Fig. 3 Kaplan-Meier analysis for event-free survival in patients with segment involvement score $\geq 4$ and $<4$

"warranty period" of lacking obstructive coronary stenoses expires after 3-5 years. This is clinically important, as patients and physicians are often falsely reassured by the lack of obstructive CAD. However, the presence of plaques should be strongly considered when counseling the patient about medical or life-style interventions to reduce cardiovascular risk. These interventions are generally intended as life-long therapies and thereby may have a significant benefit on long-term follow-up.

Limitations

Several methodological limitations of the present manuscript should be acknowledged, including the single-center design and the limited number of patients. Any preliminary 
Table 4 Predictors of events at univariate and multivariate analyses
$C I$ confidence interval, $N A$ not applicable, $N S$ non significant, $H R$ hazard ratio, $C A C S$ coronary artery calcium score

\begin{tabular}{llll}
\hline Predictors & $\begin{array}{l}\text { Univariate HR } \\
(95 \% \mathrm{CI})\end{array}$ & $p$ value & $\begin{array}{l}\text { Multivariate HR } \\
(95 \% \mathrm{CI})\end{array}$
\end{tabular}

Major adverse cardiac events (death, myocardial infraction, revascularisation)

Clinical characteristics

$\begin{array}{lllll}\text { Age (years) } & 1.03(1.00-1.10) & 0.041 & \text { NA } & \text { NS } \\ \text { Female gender } & 0.65(0.34-1.24) & \text { NS } & \text { NA } & \text { NS } \\ \text { History of CAD } & 2.47(1.28-4.80) & 0.007 & \text { NA } & \text { NS } \\ \text { Previous MI } & 2.19(0.97-4.91) & \text { NS } & \text { NA } & \text { NS } \\ \text { Cardiovascular risk profile } & & & & \\ \quad \text { Hypertension } & 1.10(0.59-2.04) & \text { NS } & \text { NA } & \text { NS } \\ \text { Hypercholesterolemia } & 1.50(0.82-2.76) & \text { NS } & \text { NA } & \text { NS } \\ \text { Diabetes mellitus } & 1.98(0.98-4.04) & \text { NS } & \text { NA } & \text { NS } \\ \text { Smoking } & 2.73(1.46-5.11) & 0.002 & \text { NA } & \text { NS } \\ \text { CACS } & 1.00(1.00-1.01) & <0.001 & \text { NA } & \text { NS } \\ \text { CT findings } & 13.88(1.91-100.73) & 0.009 & \text { NA } & \text { NS } \\ \text { Presence of coronary plaques } & 3.76(2.04-6.92) & <0.001 & 2.28(1.05-4.95) & 0.036 \\ \text { Presence of coronary stenosis } & 1.21(1.12-1.31) & <0.001 & 1.18(1.06-1.31) & 0.002 \\ \text { Segment involvement score } & & & & \end{array}$

conclusion drawn from the present data awaits confirmation in forthcoming larger multicentric and multinational CT registries.

This small sample size is related to the fact that we included the first patients to be scanned in our department with a 64-slice CT scanner starting in 2005 to obtain the longest follow-up possible. The limited sample size precluded to perform extensive multivariate Cox proportional hazards models to assess the independent predictive value of vessel distribution pattern or coronary plaque composition on long-term prognosis. CCTA was performed using spiral acquisition with retrospective ECG-gating. Although ECGmodulation of the tube current was performed, this protocol is associated with a significantly higher radiation exposure compared to the currently recommended prospectively triggered step-and-shoot protocols [17]. However, the spiral protocol was the standard clinical protocol used in our center prior to 2007-2008. The drop-out rate of 50 patients (19\%) due to insufficient CCTA image quality and loss of follow up is considerably high. This may be related to the initial learning curve with 64-slice $\mathrm{CT}$ in the early phase of the study and the long-follow-up, respectively. The current use of clinical CCTA is focused on patients with low pre-test probability, as the strength at CCTA is the high negative predictive value. In the early years, CCTA was applied even in higher pre-test likelihood populations explaining the relatively high $\mathrm{CAD}$ prevalence in the study population.

\section{Conclusion}

Patients with normal coronary arteries on CCTA have an excellent prognosis on long-term follow-up of more than
6 years, while outcome is progressively worse in patients with nonobstructive and obstructive CAD. The present study extends the proven predictive value of CCTA in short-term follow-up studies over a longer observation term of more than 6 years.

Acknowledgments The study was supported by Grants from the Swiss National Science Foundation to PAK. Furthermore, we thank Ennio Mueller and Gentian Cermjani for their excellent technical support.

Conflict of interest None declared.

\section{References}

1. Abdulla J, Asferg C, Kofoed KF (2011) Prognostic value of absence or presence of coronary artery disease determined by 64-slice computed tomography coronary angiography a systematic review and meta-analysis. Int $\mathbf{J}$ Cardiovasc Imaging $27: 413-420$

2. Gaemperli O, Valenta I, Schepis T, Husmann L, Scheffel H, Desbiolles L et al (2008) Coronary 64-slice CT angiography predicts outcome in patients with known or suspected coronary artery disease. Eur Radiol 18:1162-1173

3. Min JK, Shaw LJ, Devereux RB, Okin PM, Weinsaft JW, Russo DJ et al (2007) Prognostic value of multidetector coronary computed tomographic angiography for prediction of all-cause mortality. J Am Coll Cardiol 50:1161-1170

4. van Werkhoven JM, Gaemperli O, Schuijf JD, Jukema JW, Kroft LJ, Leschka S et al (2009) Multislice computed tomography coronary angiography for risk stratification in patients with an intermediate pretest likelihood. Heart 95:1607-1611

5. Motoyama S, Sarai M, Harigaya H, Anno H, Inoue K, Hara T et al (2009) Computed tomographic angiography characteristics of atherosclerotic plaques subsequently resulting in acute coronary syndrome. J Am Coll Cardiol 54:49-57

6. Min JK, Dunning A, Lin FY, Achenbach S, Al-Mallah M, Budoff MJ et al (2011) Age- and sex-related differences in all-cause 
mortality risk based on coronary computed tomography angiography findings results from the International Multicenter CONFIRM (Coronary CT Angiography Evaluation for Clinical Outcomes: an International Multicenter Registry) of 23,854 patients without known coronary artery disease. J Am Coll Cardiol 58:849-860

7. Andreini D, Pontone G, Mushtaq S, Bartorelli AL, Bertella E, Antonioli L et al (2012) A long-term prognostic value of coronary CT angiography in suspected coronary artery disease. JACC Cardiovasc Imaging 5:690-701

8. Sozzi FB, Civaia F, Rossi P, Robillon JF, Rusek S, Berthier F et al (2011) Long-term follow-up of patients with first-time chest pain having 64-slice computed tomography. Am J Cardiol 107:516-521

9. Austen WG, Edwards JE, Frye RL, Gensini GG, Gott VL, Griffith LS et al (1975) A reporting system on patients evaluated for coronary artery disease. Report of the Ad Hoc Committee for Grading of Coronary Artery Disease, Council on Cardiovascular Surgery, American Heart Association. Circulation 51:5-40

10. Leber AW, Knez A, von Ziegler F, Becker A, Nikolaou K, Paul S et al (2005) Quantification of obstructive and nonobstructive coronary lesions by 64-slice computed tomography: a comparative study with quantitative coronary angiography and intravascular ultrasound. J Am Coll Cardiol 46:147-154

11. Agatston AS, Janowitz WR, Hildner FJ, Zusmer NR, Viamonte M Jr, Detrano R (1990) Quantification of coronary artery calcium using ultrafast computed tomography. J Am Coll Cardiol $15: 827-832$
12. Thygesen K, Alpert JS, Jaffe AS, Simoons ML, Chaitman BR, White HD (2012) Third universal definition of myocardial infarction. Eur Heart J 33:2551-2567

13. Fluss R, Faraggi D, Reiser B (2005) Estimation of the Youden index and its associated cutoff point. Biom J 47:458-472

14. Ostrom MP, Gopal A, Ahmadi N, Nasir K, Yang E, Kakadiaris I et al (2008) Mortality incidence and the severity of coronary atherosclerosis assessed by computed tomography angiography. J Am Coll Cardiol 52:1335-1343

15. Hadamitzky M, Taubert S, Deseive S, Byrne RA, Martinoff S, Schomig A et al (2013) Prognostic value of coronary computed tomography angiography during 5 years of follow-up in patients with suspected coronary artery disease. Eur Heart J 34:3277-3285

16. Chang SM, Nabi F, Xu J, Peterson LE, Achari A, Pratt CM et al (2009) The coronary artery calcium score and stress myocardial perfusion imaging provide independent and complementary prediction of cardiac risk. J Am Coll Cardiol 54:1872-1882

17. Abbara S, Arbab-Zadeh A, Callister TQ, Desai MY, Mamuya W, Thomson L et al (2009) SCCT guidelines for performance of coronary computed tomographic angiography: a report of the Society of Cardiovascular Computed Tomography Guidelines Committee. J Cardiovasc Comput Tomogr 3:190-204 